Language and Language Teaching Journal http://e-journal.usd.ac.id/index.php/LLT Sanata Dharma University, Yogyakarta, Indonesia

\title{
VOCABULARY ENHANCEMENT OF FEMALE ESL LEARNERS THROUGH SHORT STORIES: A RURAL/ URBAN PERSPECTIVE
}

\author{
Naseer Ahmed \\ Lahore Garrison University, Lahore, Pakistan \\ naseerahmed159@yahoo.com \\ DOI: doi.org/10.24071/1lt.2017.200207
}

received 5 July 2017; revised 30 August 2017; accepted 27 September 2017

\begin{abstract}
Teaching English has progressed rapidly with the changing requirements of society. Current study has not only the purpose of testing vocabulary enhancement by short stories but also monitors its effects on rural and urban population at secondary level. Present study utilizes Pre-test, post-test experimental design. Before the commencement of study, 50 students took their pre-test from rural site and 50 students took their pre-test from urban site. Only those 20, 20 students were selected from both sites whose accumulative score was almost the same. After this, five short stories were taught to both groups for five weeks with the same methodology. After the completion of coaching, a post-test was conducted. Marks of pre-test and post-test of both rural and urban groups were compared to see difference in learning. Data was analyzed statistically by using SPSS 20 for windows. Analysis of data proved that urban group had statistically significant improvement as compared to rural group.
\end{abstract}

Keywords: short stories, vocabulary building, ESL, ELT

\section{Introduction}

Language learning is of prime importance in almost every walk of life. Without sufficient vocabulary, one faces difficulty in the expression of views. A lot of work has been done to devise different novel and interesting teaching methodologies to improve vocabulary. Use of literature in language teaching has been appreciated by a lot of researchers especially by Maibodi (2008) and Vaughnetal (2004). Nasreen (2010) further strengthens this view by saying that "short-stories" will create a marked difference in the process of language teaching and improving vocabulary.

Students in Pakistani schools are taught English from the very first class but most of graduates are unable to use English fluently and correctly which is the result of rote-learning system. To cope with this situation, a number of changes are being introduced in the field of education which is quite evident from the conversion of Urdu medium schools into English Medium by Government of Pakistan. Waqas (2011) further supports it by saying that Punjab government has felt the importance of English language by making it a compulsory subject from class one. Government teachers are regularly trained to teach English efficiently. Present study is designed to do a comparative analysis of rural and urban students regarding vocabulary enhancement through short stories. It was hypothesized for 
the present study that short stories will prove to be an effective tool in vocabulary enhancement of both rural and urban students. It was also to be tested that for which group this methodology was more suitable. Moreover, it is an effort to reduce tension and anxiety among students as it is really useful not only for teachers but also for students, parents and policy makers to use new techniques in language teaching.

\section{Number of Vocabulary Items Learners Must Know}

Many researchers have tried to estimate the number of lexical items that native speakers of any language know to assess that how many words other than non native speakers must know to learn the language. For a native speaker, this estimate varies between 12,000 to 20,000 words depending on the level of education (Goulden, Nation and Read, 1990). Exposure of a few words can lead to greater comprehension for non native speakers. For instance, the students who have the knowledge of most frequent 20,000 words would be able to understand almost $80 \%$ of the words in an average text and if the knowledge of words is 50,000 , then learner's understanding is increased to $88.7 \%$ (Francis and Kucrera, 1982). For spoken language 1,800 words make up over $80 \%$ of the spoken corpus.( Mc Carthy and Carter, 2007).

\section{Vocabulary Enhancement through Short Stories}

Short stories are also considered to be very powerful teaching tools especially for vocabulary enhancement. According to Pesola (1991), storytelling gives more fruitful results with young language learners than anyone else. Isbell (2002) further elaborates it by saying that children enjoy only those stories which include repetitive phrases and unique words. Meyer (2000) is also of the view that stories contain culture load which refers to the way in which language and culture are related and the amount of cultural knowledge which is required to understand meanings in order to participate in activities. Students should know not only the words but also cultural background and they should learn the vocabulary in context.

Short stories also help children to recall or reread the story to build their conceptual knowledge. Stories help learners to develop concepts about new words, print and books as well as evaluating students current language levels (Morrow, 2001). Students' language proficiency is also developed with the help of such practices. Richgels (2000) is of the view that story recall provides students with an opportunity to organize the sequence of events, to utilize the vocabulary items present in the story and to expand children's comprehension of the world as well. Story recall is not only a research tool for the researchers as it gives a large amount of data to gain insight into learner's comprehension processes (Goodman, 1982) but also an instructional strategy that has the potential to improve many literary skills.

\section{Attitudes towards Vocabulary Enhancement through Short Stories}

It is proved by research that students have a positive attitude towards short stories methodology. Maibaodi (2008) conducted a study on learning English through short stories on 200 female adult, Persian speaking university undergraduates and found that they showed positive attitude towards short stories. Erakaya (2003) is of the view that short stories enable the students to engage all 
the four skills of English language. Lao and Krashen (2000) conducted a study between two groups. The results of first group showed their improvement through reading literary texts and the other group showed results of non literary texts. Oster (1989) also affirms the importance of "literature by saying that literature helps students to write more creatively" (p. 85). Nasreen (2010) also conducted a study on higher school level students and found a positive response of research population towards this strategy. Khatib (2011) conducted a study at Allameh Tabataba'i University Iran with 24 students in one group and 21 in other group. This study suggests that short stories remained effective in improving student's linguistic skills regardless of the way used to teach to students. Kirkgoz (2012) conducted a study on 21 Turkish university students regarding their responses towards short stories. The findings of this study suggested that short stories contribute a lot in the overall understanding of the students. Strodt-Lopez (1996) used short stories to improve comprehension skills of the students. Findings signify the importance of short stories. Pardebe (2012) also used short stories on Indonesian students to improve their linguistic proficiency and the findings of this study suggested that utilization of short stories improved students' language proficiency. Murdoch (2002) is of the view that short stories enhance the linguistics and paralinguistic competence of the students. Ellis and Brewster (1991) are of the view that stories motivate the students towards learning English as a foreign language. The research question is "Does rural/urban setting affect vocabulary enhancement and to what extent can vocabulary be enhanced through short stories in rural and urban settings?"

\section{Method}

As mentioned earlier that out of 100 students, only 40 selected students of class 9th participated in this study. Out of these forty students, twenty belonged to rural site i.e. GG High School SherGarh District Okara and twenty belonged to GG High School Hujra Shah Muqeem District Okara. It was kept in mind that accumulative score of both groups in pre-test was almost the same which showed that students of both groups were almost of the same intellectual level.

Pre-test, containing $10 \mathrm{MCQs}$ out which five were related to antonymous and 5 were related to synonyms. The lexemes were selected from the textbook of class 8th that has been read by both rural and urban students. Post-test also contained same number of questions on the same pattern that was used in pre-test. The difference was that now the content of the post test was selected from the short stories which were taught by the researcher.

Before the actual start of the study, formal consent of the students was sought. 100 students took pretest and the result of pre-test marks enabled the researcher to select twenty students from rural and twenty from urban site. On the very first day of commencement of classes, every student was provided with a short story and it was read aloud in the class room. Students were asked to underline unfamiliar words while reading and they were explained these difficult words with the help of TPR (total physical response) along with contextual clues, key word method. One week was spent on each story. Short stories were available in the class room for students. Their availability in the classroom facilitated the 
students for self study. The rest of the four short stories were taught to both rural and urban group students through the same methodology as explained above. At the end of the whole intervention, all the students appeared in a very formal posttest session at their respective sites.

\section{Findings and Discussion}

Results of pre-test showed that mean score and standard deviation in pre-test for rural group were 6.80 (2.419) and for rural group mean score and standard deviation were 6.60 (1.429). These results showed that both groups had almost the same results. The detail of this data is showed in table 1.

Table 1: Mean score and standard deviation in pre-test of both groups

Variable Group No. of Students Mean Score Std.

\section{Deviation}

\begin{tabular}{llccc}
\hline Pre-test & Rural & 20 & 6.80 & 2.419 \\
& Urban & 20 & 6.60 & 1.429 \\
\hline
\end{tabular}

Results of independent samples t-test proved that there was no significant difference in the pre-test mean scores as $\mathrm{t}(38)=0.352, \mathrm{p}=0.727, \alpha=0.05$.

Post-test marks of both urban and rural groups showed that there was an improvement in the mean score and standard deviation of both groups. Mean score and standard deviation for rural group was 7.65 (1.089) and for urban group, mean score and standard deviation in post test were $7.85(0.988)$. So increase in mean score of post-test for rural group was from 6.80 to 7.65 (difference $=1.00$ ) and this increase for urban group was from 6.50 to 7.85 (difference $=2.35)$. Table 2 and 3 proved that both groups had performed better than before.

Table 2: Mean score and standard deviation in post-test for both groups

Variable Group No. of Students Mean Score

\begin{tabular}{lllll}
\hline Post-test & Rural & 20 & 7.65 & 1.089 \\
& Urban & 20 & 7.85 & 0.988 \\
\hline
\end{tabular}

Std.

Deviation 
LLT, e-ISSN 2579-9533, p-ISSN 1410-7201, Vol. 20, No. 2, October 2017

Table 3: Mean change in test-score for both groups

$\begin{array}{llll}\text { Variable } & \text { Pre-test } & \text { Post-test } & \text { Change }\end{array}$

\begin{tabular}{lcccccc}
\hline Post-test & Rural & Urban & Rural & Urban & Rural & Urban \\
& 6.80 & 6.50 & 7.65 & 7.85 & 0.85 & 1.35 \\
\hline
\end{tabular}

Post-test results proved that rural group had improved much more in its mean score of post-test. Further analysis of improvement in post-test of both groups was conducted by using paired samples t-test. Paired samples t-test revealed that there was a statistically significant difference in post-test score of rural group as $\mathrm{t}(19), \mathrm{p}=0.163, \alpha=0.05$.

Paired samples t-test revealed that there was a significant difference in the pre-test and post-test marks of urban group as $\mathrm{t}(19)=-2.37, \mathrm{p}=0.01, \alpha=0.05$.

It clearly proves the hypothesis that location has an effect on the learning of the students. So, it can be concluded that in terms of statistical significance, urban group had improved much more than the rural group. All this change was due to the change in location of school. Short stories for vocabulary enhancement proved to be effective for both rural and urban groups but there was a significant difference in improvements of rural and urban students. One possible reason was the past exposure of urban students to short stories in the form of rhymes having short stories in them that they used to have at the beginning level of school. For rural students, it was quite a new methodology due to which they couldn't perform like urban students. It may also be concluded that we can have wonderful outputs from students by introducing short stories from the very beginning level at school. All the possible steps were taken to provide controlled environment to both rural and urban groups of this study. Hard copies of short stories were provided to each student but before leaving the classroom, after lecture they were asked to submit these copies. So that no group member can have any help from her home. This was done because urban students might have some help from their parents or tuition teachers but rural students are commonly not provided with such type of guidelines. So students were asked to do everything at their own honestly and were prohibited to seek any type of help except teacher. It was also tried at researcher's level best that all the rural participants should belong to purely rural areas. Same precaution was also taken into account for urban group. Most of the participants of this study found vocabulary enhancement through short stories an interesting methodology. These were the core after effects of this methodology. Yet there was a significant difference between the outputs of rural and urban groups.

\section{Conclusion}

Rural students expressed a wish that this methodology should be introduced from the primary level. In an informal session, they said that teachers should be properly trained by government for successful implementation of this strategy. It 
can be concluded that vocabulary enhancement through short stories is an effective methodology and it enhances vocabulary of urban secondary level students more than the rural secondary level students. Government should take steps to introduce literature for language teaching not only at secondary level but also at the beginning level.

\section{References}

Ellis, G., \& Brewster, J. (1991). The storytelling handbook: A guide for primary teacher of English. Hamond Swath: Penguin.

Erakaya, R. O (2003). Benefits of using short stories in the EFL context. Asian EFL Journal, 1(3).

Goodman, M. (1982). Retelling of literature and the comprehension process. Theory into Practice, 21(4), 300-307.

Isbell, R. (2002). Telling and Retelling Stories Learning Language and Literacy Young Children, 57 (2), 26-30.

Khatib, S. (2011). Applying the reader response approach in teaching English short stories to EFL students. Journal of Language Teaching and Research, 2(1), 151-159.

Kirkgoz, Y. (2012). Incorporating short stories in English language classes. Novitas Royal, 6(2), 110-125.

Lao, C. Y and S. Krashen (2000). The impact of popular literature study on literacy development in EFL: More evidence for the power of reading. System, 28, 261-270.

Maibodi, H.A. (2008). Learning English through short stories. Iranian Journal of Language Studies (IJLS), 2(1), 41-72.

Meyer, L. (2000). Barriers to meaningful instruction for English learners. Theory into Practice, 39(4), 228-236.

Morrow. L. M. (2001). Literary development in the early years: Helping children read and write ( $4^{\text {th }}$ ed.). Boston: Allyn and Bacon.

Murdoch, G. (2002). Exploiting well-known short stories for language skills development. IATEFLLCS SIG Newsletter, 23, 9-17.

Nasreen, (2010). Improving vocabulary through short stories at higher school level (PGD Thesis, Punjab University).

Oster, J. (1989). Seeing with difference eyes: Another view of literature in the ESL class. TESOL Quarterly, 23 (1), 85-103.

Pesola, C. A. (1991). Culture in the elementary foreign language classroom. Foreign Language Annals, 24 (4), 331-346.

Richgels \& McGee, L. M., (2000). Literary beginnings: Supporting youth readers and writers $\left(3^{\text {rd }}\right.$ ed.). Boston: Allyn and Bacon.

Vaughn,S., \& Hickman, P.(2004). Story book reading: Improving vocabulary and comprehension for English language learners. Atahe Reading Teacher, 57(8), 720-730.

Waqas, S.A. (2011). The status of English language teaching in Pakistan. ELT Weekly, 3(88), 10-19. 